\title{
The Mediation Effect of Emotional Experience between Emotion Labor and Job Engagement
}

\author{
Shang-Ping Lin ${ }^{1}$, Yin-Ying Wang, ${ }^{1, *}$ Wen-Ling Hsu ${ }^{2}$, Ching-Han Fang ${ }^{1}$ \\ ${ }^{1}$ Department of Business Administration, National Yunlin University of Science and Technology, Taiwan \\ ${ }^{2}$ Department of Golden-Ager Industry Management, Chaoyang University of Technology, Taiwan
}

Copyright $\mathrm{O} 2015$ by authors, all rights reserved. Authors agree that this article remains permanently open access under the terms of the Creative Commons Attribution License 4.0 International License

\begin{abstract}
Job engagement is a key issue that deserves attention within the framework of emotional labor. This is due to its role in increasing employee happiness and productivity. Past literature rarely examined the relationship between emotional labor and job engagement, which composes the major research purpose of this study. The result shows that positive emotional expression, faking negative emotions and dealing with other negative emotions was positively associated with job engagement. Happiness, aggravation, sadness, inferiority have mediating effects towards the relationship between positive emotional expression and job engagement, but the anxiety was not significant. Finally, few researches have been conducted in the past to examine the relationship between emotional labor and job engagement. Therefore, the hypothesis is a general in terms of reference inference, and might not focus on only the relationship between the two factors. Supporting evidence in terms of literature and research material should be further supplemented in the future, in order to construct a more solid theoretical framework.
\end{abstract}

Keywords Emotional Labor, Emotional Experience, Job Engagement

\section{Introduction}

Since the concept of emotional labor was proposed by Hochschild (1983), the study of emotion has evolved from the personal sphere into its commercialization. Organizations have started to strategize various methods and management measures to allow for employees to demonstrate the most appropriate emotional expressions in order to satisfy customer expectations. Furthermore, organizations can integrate organizational strategy with various human resource management systems to specify and regulate how employees express appropriate emotions while performing their duties and assignments (Anderson, 1993; Ashforth and Humphrey, 1995; Rafaeli and Sutton,
1988). Consequently, when work regulations of employees involve emotional expression and control, or when personal effort to regulate emotions is needed by the employee in order to satisfactorily perform their roles within the organization, it can be defined as an aspect of emotional labor (Wu, 2013).

Emotion experience is a complex phenomenon, from a purely subjective perception to action tendencies, behavior observation and physiological change included within its context (Luca, Deiner and Larsen,2003). Those findings indicate the growing importance of emotional or sentimental expression of employees within an organization (Ashforth and Humphrey, 1993; Grandey, 2000; Morris and Feldman, 1996). Whether employees are asked to conceal or suppress negative emotions and present a positive emotion in order to comply with emotional requirements stipulated within the organization in work proceedings (Brotheridge and Grandey, 2002; Hochschild, 1983; VanMaanen and Kunda, 1989). Employees are therefore required to naturally express agreeable emotions while performing their job duties, and appropriately manage personal emotions in order to meet organizational requirements.

Employees, when faced with organizational requirements and regulations, demonstrate conflicting psychological responses, and will base their decision criteria on internal self-assessment and external environmental factors, in order to further calibrate and measure role played by the employee (Kahn, 1990). Under these circumstances, employees will receive interferences caused by organizational interactions with other parties and organizational requirements on emotional expressions of employees. This will consequentially result in multiple stress factors for the employee, and a higher tendency to perceive frustration and setbacks. Employees can produce various responses when confronting setbacks: job engagement or job withdrawal can occur. When employees successfully overcome negative emotions, such as anger and sad, etc., they will transform the obstacle into a driving force, with full dedication and pride in the job. (Bakker, Schaufeli, Leiter and Taris, 2008; Jones \& Harter, 2005). 
Those prior finding support the view that job engagement is a key issue that deserves attention within the framework of emotional labor. This is due to its role in increasing employee happiness and productivity (Schaufeli and Salanova, 2007). Past literature rarely examined the relationship between emotional labor and job engagement (Lu and Guy, 2014; Grandey, 2000), which composes the major research purpose of this study.

\section{Hypotheses}

Kahn(1990) proposed the concept of "Work Engagement" and defined it as "'the harnessing of organization members' selves to their work roles; in engagement, people employ and express themselves physically, cognitively, and emotionally during role performances.", and viewed this as a form of job engagement. This concept is focused on personal and job performance and the relationship dynamic between the two (person-role relationships), including employee's involvement in their job functions as defined in the job specification (Lawler and Hall, 1970; Lodahl and Kejnar, 1965); organizational commitment (Mowday, Porter, and Steers, 1982), and a sense of detachment and alienation in their jobs (Seeman, 1972). The above demonstrates job involvement not only as an employee's set job performance, but also the emotional state of the employee that fluctuates and changes along with the job assigned.

In an attempt to fit into a pre-defined role as required by the organization, very often the employee will put on a "fake mask", and conceal emotions or suppress true thoughts and feelings in order to properly perform their tasks or interact with other people. Therefore, employees often attempt to try making this disguise more genuine and believable in order to isolate and conceal true performance or behavior (Hochschild, 1983). If this mode of behavior is undertaken for a long period of time, It often induces a sense of imbalance and discord for the employee, which could result in a misalignment of internal emotions and outside performance and behavior. The employee might not know how to regulate their own self and the role required in their jobs, and even less likely will they find meaning and value in their jobs, with the consequence being a decline in job performance and motivational effect.

Employees who need to conceal emotions while on their job posts actually need to dedicate a lot of effort into accomplishing this (Brotherige and Lee, 2002). If more resources are needed to conceal true personal emotions, then less effort is paid to execute the job responsibilities. On the contrary, if the employee can harness the true emotions required in their jobs together with true feelings, and induce a positive outcome in their job attitude and emotional expression, whilst also keeping positive faith in their actions (Grandey 2003), then the employee will treat his/her employer and job in a positive manner (Rafaeli and Sutton, 1987). Once the employee participates and has affinity for his/her job, they will gradually motivate themselves to manifest appropriate expressions of emotion, and are willing to continue this uniformity in true inner feelings and external performance (expression of emotion). After experiencing such emotional labor, employees also have a tendency to believe these experiences to be worthwhile, useful, and with value (Kahn, 1990), which ultimately allows them to play the emotional role as required and defined by the organization. Summing up the above, this study proposed that the relationship between emotional labor and job engagement are influenced by the mediating effects of emotional experience, with the hypothesis below:

\section{$H_{1}$ : The mediating effect of Emotional experience on the relationship between emotional labor and job engagement.}

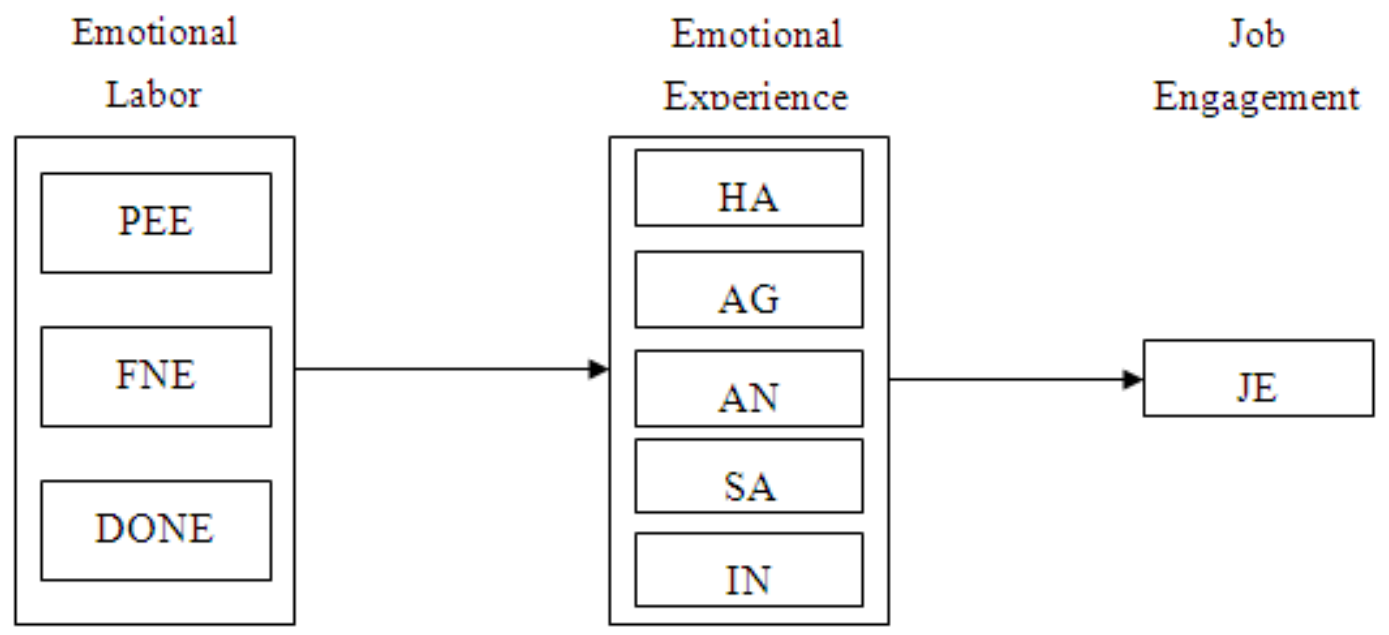

Figure 1. Research framework 


\section{Methods}

\section{Samples and Procedures}

This study attempted to analyze the perspective of emotional labor by using measurement tools in past literature. First, the demographic variables were collected, such as sex, age, married, education and seniority. Second, the literature of emotional labor, emotional experience, and job engagement was collected. The responders are derived from general employees in companies across Taiwan, and examined the relationship between emotional labor (EL), emotional experience (EE), and job engagement (JE). This was to ensure the fit of reliability and validity of research outcome. After the removal of incomplete questionnaires, a total of 154 questionnaires, with a return rate of $96.25 \%$.

\section{Measures}

Contextualization is the positioning of research into a certain context. Therefore, this questionnaire was designed into four parts to developed questionnaires by researchers in Taiwan. The scale ranging from 1, "almost never," to 5, "very often". The first facet measured emotional labor and asked interviewees the strategies adopted to accommodate regulations governing emotional expressions in their respective workplaces. The scale was developed by Lin (2000) and $\mathrm{Wu}(2003)$. The questionnaire including positive emotional expressions (PEE), faking negative emotions (FNE), and dealing with other negative emotions (DONE). Examples from the five-item included "you need to express certain behaviors to communicate a certain image as required by the position". The second part is measurement of emotional experience, inquiring what emotional responses were expressed within certain occupational situations. We used the scales developed by Plutchick (1980) and Jean (1998). The scales included "Happiness (HA)", "aggravation (AG)", "anxiety (AN)", "sadness (SA)", and "inferiority (IN). Examples from the five-item included "Events that occurred during work that induced sad emotions". The third part is the measurement of job engagement, which referenced Schaufeli, Salanova, Gonzalez-Roma and Bakker (2002). Examples from the five-item included "I feel pride in my work". The fourth part is the measurement demographic variable to describe the data gathered, with an aim to understand sample data structure and basic characteristics.

\section{Results}

\section{Descriptive Statistics and Correlations}

Descriptive Statistics of this variables in this study is showing in Table1, including the Mean, S.D. and correlations matrix between variables.

Table 1. Descriptive statistics and correlations analysis

\begin{tabular}{cccccccccccc}
\hline & & Mean & SD. & PEE & FNE & DONE & HA & AG & AN & SA & IN \\
\hline \multirow{2}{*}{ EL } & PEE & 3.93 & .72 & 1 & & & & & & & \\
& FNE & 3.38 & .96 & $.592^{* *}$ & 1 & & & & & & \\
& DONE & 3.46 & .92 & $.603^{* *}$ & $.958^{* *}$ & 1 & & & & \\
& HA & 3.11 & .48 & $.299^{* *}$ & $.195^{*}$ & $.195^{*}$ & 1 & & & \\
& AG & 2.81 & .60 & -.048 & $.185^{*}$ & $.174^{*}$ & $.207^{* *}$ & 1 & & & \\
EE & AN & 2.86 & .73 & -.096 & .153 & .154 & $-.199^{*}$ & $.499^{* *}$ & 1 & & 1 \\
& SA & 2.21 & .66 & -.071 & $.195^{*}$ & .149 & -.138 & $.520^{* *}$ & $.518^{* *}$ & 1 \\
& IN & 2.49 & .69 & -.022 & .132 & $.163^{*}$ & .060 & $.285^{* *}$ & $.358^{* *}$ & $.351^{* *}$ & 1 \\
JE & JE & 3.17 & .90 & $.464^{* *}$ & $.316^{* *}$ & $.280^{* *}$ & $.647^{* *}$ & $-.415^{* *}$ & $-.275^{* *}$ & $-.165^{*}$ & $-.215^{* *}$ \\
\hline
\end{tabular}

$1^{* * *} \rho<.01,{ }^{*} \rho<.05$; 2.PEE: Positive emotional expression, FNE: Faking negative emotions, DONE: Dealing with other negative emotions, HA: Happiness, AG: Aggravation, An: Anxiety, Sa: Sadness, In: Inferiority.

\section{Tests of Hypotheses}

Table 2. The results of mediating effect

\begin{tabular}{|c|c|c|c|c|c|c|c|c|}
\hline \multirow{2}{*}{ Path } & \multicolumn{2}{|c|}{ Path coefficient } & \multirow{2}{*}{ Path } & \multicolumn{2}{|c|}{ Path coefficient } & \multirow{2}{*}{ Path } & \multicolumn{2}{|c|}{ Path coefficient } \\
\hline & Indirect & Total & & Indirect & Total & & Indirect & Total \\
\hline $\mathrm{PEE} \rightarrow \mathrm{JE}$ & - & $.452^{* *}$ & $\mathrm{FNE} \rightarrow \mathrm{JE}$ & - & $.496^{*}$ & $\mathrm{DONE} \rightarrow \mathrm{JE}$ & - & -.468 \\
\hline $\mathrm{PEE} \rightarrow \mathrm{HA}$ & .175 & .627 & $\mathrm{FNE} \rightarrow \mathrm{HA}$ & .028 & .524 & $\mathrm{DONE} \rightarrow \mathrm{HA}$ & -.011 & -.479 \\
\hline $\mathrm{PEE} \rightarrow \mathrm{AG}$ & .075 & .527 & $\mathrm{FNE} \rightarrow \mathrm{AG}$ & -.079 & .417 & $\mathrm{DONE} \rightarrow \mathrm{AG}$ & -.022 & -.490 \\
\hline $\mathrm{PEE} \rightarrow \mathrm{AN}$ & - & - & $\mathrm{FNE} \rightarrow \mathrm{AN}$ & - & - & $\mathrm{DONE} \rightarrow \mathrm{AN}$ & - & - \\
\hline $\mathrm{PEE} \rightarrow \mathrm{SA}$ & -.042 & .410 & $\mathrm{FNE} \rightarrow \mathrm{SA}$ & .106 & .602 & $\mathrm{DONE} \rightarrow \mathrm{SA}$ & -.053 & -.521 \\
\hline \multirow[t]{3}{*}{$\mathrm{PEE} \rightarrow \mathrm{IN}$} & .040 & .492 & $\mathrm{FNE} \rightarrow \mathrm{IN}$ & .056 & .552 & $\mathrm{DONE} \rightarrow \mathrm{IN}$ & .011 & -.457 \\
\hline & & & & \multicolumn{2}{|c|}{.630} & & & \\
\hline & & & & \multicolumn{2}{|c|}{33.604} & & & \\
\hline
\end{tabular}

${ }^{* *} \rho<.01,{ }^{*} \rho<.05$ 


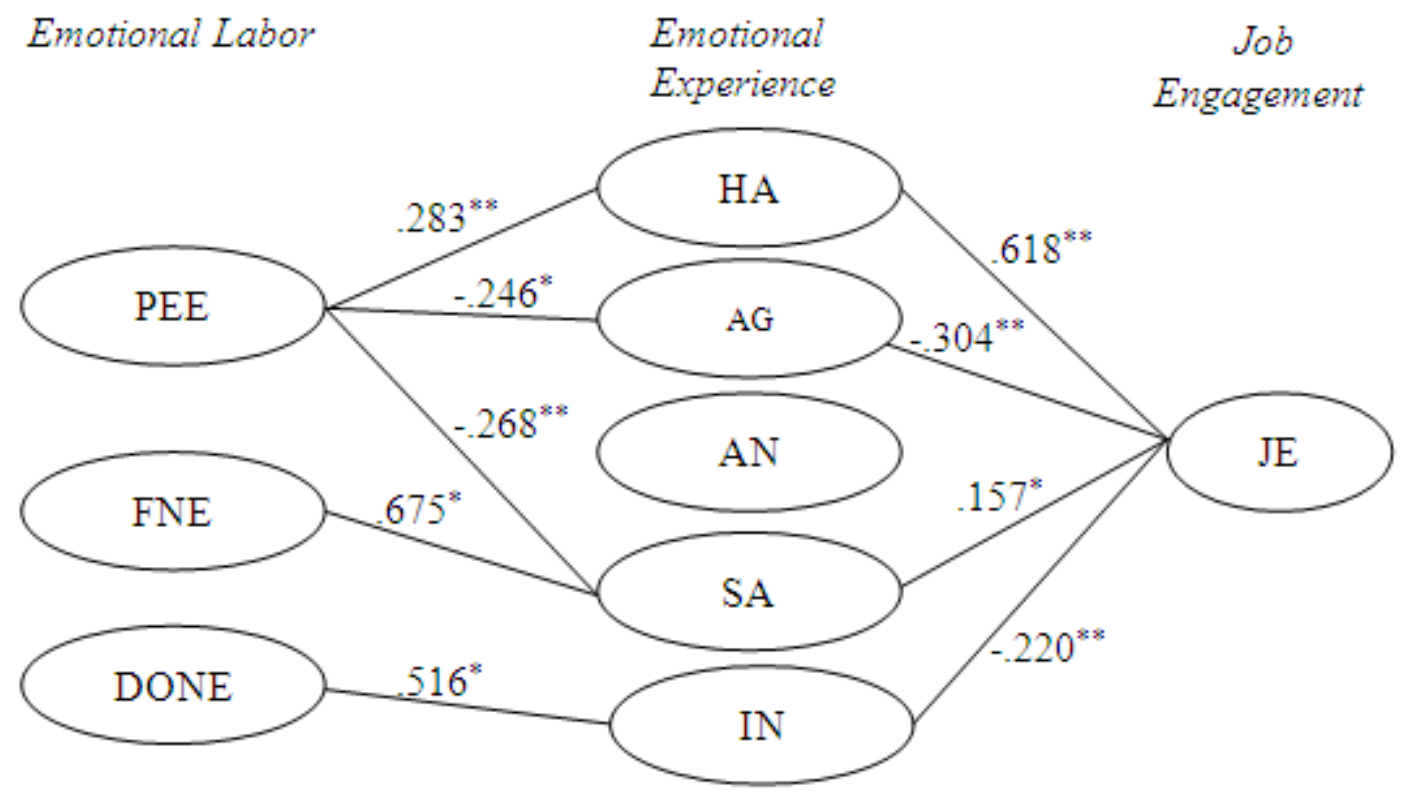

Figure 2. The mediated effects of variables.

Table 2 shows the results of mediating effect. This study used SPSS statistics to analysis mediating effects. The Positive emotional expressions $(\beta=.452, \mathrm{p}<.01)$ and faking negative emotions $(\beta=.496, p<.05)$ were positive associated with job engagement. Dealing with other negative emotions was negative associated with job engagement, but it was not significant. The results of the mediated test these variables, showing that HA has a partially mediate affect between PEE and JE. However, AG and SA have partially mediate affect between PEE and JE, but it was negative. SA also has partially mediate affect and will influence faking negative emotions on job engagement. Lastly, dealing with other negative emotions will affect job engagement due to inferiority emotions, which indicates that a feeling of inferiority has mediating effect.

\section{Conclusions and Discussion}

\section{Conclusions}

Based on the results, the positive emotional expression, faking negative emotions and dealing with other negative emotions was positively associated with job engagement, supporting hypothesis 1 . That is, emotional labor is the appropriate expression of emotion required or expected by the organization on the employee (Ashforth and Humphrey, 1993). When this becomes a source of stress for the employee, job engagement will reflect an individual's regard and emphasis towards the job (Lodahl and Kejner, 1965; Rabinowitz and Hall, 1977). If the employee attempts to undertake different emotional strategies to fulfill the organization's requirements during work, the emotions they exhibit might possibly be authentic. The willingness to adjust emotions and feelings from the inside will help the employee to exhibit a higher sense of passion and energy towards the job. In attempting to verify the relationship between emotional labor and emotional experience, this study has found that inferiority is the only emotion that has no significant. The reason from the fact that service industries exist to serve customers, so no matter what customers or supervisors the employee meets, it is still considered to be a part of the job, and hence has a tendency to induce certain emotions (for example: happiness or aggravation). Inferiority is a passive emotion that exhibits one's lack of faith to one's ability. For the service industry, which contains relatively few barriers into entry and employment and inherently requires the employee to respect and provide great service to the customer, employees perceived feelings of inferiority is more unlikely to appear and measured.

Happiness, aggravation, sadness have mediating effects towards the relationship between positive emotional expression and job engagement. This also shows that when employees have more positive emotional expression, it will perceive that decrease aggravation and sadness, and they will increase job engagement. This conclusion corresponds to Guy et al (2008) and Hsieh et al (2012)'s previous research, and describes how if employees have the ability to express authentic emotions during work, they will be more inclined towards actively engaging in their jobs. However, if they are required to conceal their own emotions to fulfill organizational requirements and customer expectations, then their perception of engagement in their jobs will decrease. Sadness has a mediating effect between faking negative emotions and job engagement, it means that employees more often applied this way, and then they will more often feel sadness, but still increase job engagement. This result was failing to support hypothesis, and might result from the fact that although employees might feel sadness, but in order to continue working at the 
organization, they will still ask themselves to continue committing to job engagement. Inferiority has a mediating effect between dealing with other negative emotions and job engagement. The result was consistent on the organizational contexts. When the employee's responsibility is to deal with other's negative emotions, the employee might perceive his/her own shortcomings or faults in the mediating process. Furthermore, mishandling of the situation might also result in dissatisfaction on both sides. In the long term, this will decrease passion for the job and increase the risk of job burnout and considerations to resign from the job.

\section{Limitations and Suggestions}

This study adopts employees of various companies as a mediating effect to examine the influence of emotional labor on job engagement. The result from our study was supported to the hypothesis. However, job engagement is a factor within emotional labor that deserves further attention. This is due to the fact that it will enhance the perceived well-being of the employee and increase productivity (Schaufeli and Salanova, 2007). However, few researches have been conducted in the past to examine the relationship between emotional labor and job engagement ( $\mathrm{Lu}$ and Guy, 2014). Therefore, the hypothesis is a general in terms of reference inference, and might not focus on only the relationship between the two factors. Supporting evidence in terms of literature and research material should be further supplemented in the future, in order to construct a more solid theoretical framework. On the other hand, the research was general employees from companies across different industries with a broad scope, which might result in a less detailed analysis of emotional labor. We suggest that future studies can focus on different groups in across industries and employment positions, to enlarge the applicability of the research topic. Lastly, this research only viewed one layer of measurement standards. Future research should include different levels and positions within an organization (such as: supervisors), to ensure complete links and research concept.

\section{REFERENCES}

[1] Anderson, G. Emotion and work in a lifestyle occupation. Journal of European Industrial Training, 1993, 17: 10-14.

[2] Arvey, R. D., Renz, G. L., \& Watson, W. W. Emotionality and job performance: Implications for personnel select. Personnel and Human Resources Management, 1998, 16: 103-147.

[3] Ashforth, B. E., \& Humphrey R. H. Emotional labor in service roles: The influence of identity. Academy of Management Review, 1993, 18(1): 88-115.

[4] Ashforth, B. E., \& Humphrey R. H. Emotion in the workplace: A Re-appraisal. Human Relations, 1995, 48(2): 97-25.

[5] Bakker, A. B., \& Schaufeli, W. B. Positive organizational behavior: Engaged employees in flourishing organizations.
Journal of Organizational Behavior, 2008, 29(2): 147-154.

[6] Brotheridge, C. M \& Lee, R. T. On the dimensionality of emotional labor: Development and validation of the emotional labor scale. Paper presented at the First Conference on Emotions in Organization Life, San Diego, 1998.

[7] Brotheridge, C. M., \& Grandey, A. A. Emotional labor and burnout: Comparing two perspectives of "people work". Journal of Vocational Behavior, 2002, 60: 17-39.

[8] Chian-Chong, Jean. The analysis of nurses as emotional labor. Journal of human resources management, 1998, 10: 122-135.

[9] Grandey, A. A. Emotion regulation in the workplace: A new way to conceptualize emotional labor. Journal of Occupational Health Psychology, 2000, 5(1), 95-110.

[10] Grandey, A. A. When the "show must go on" : Surface acting and deep acting as determinants of emotional exhaustion and peer-rated service delivery. Academy of Management Review, 2003, 46: 86-96.

[11] Guy, M.E., Newman, M.A., \& Mastracci, S.H. Emotional labor: Putting the service in public service. Armonk, NY: M.E. Sharpe, 2008.

[12] Hochschild, A. R. The Managed Heart. CA: University of California Press, 1983.

[13] Hsieh, C.-W., Jin, M. H., \& Guy, M. E. Consequences of work-related emotions: Analysis of a cross-section of public service workers. American Review of Public Administration, 2012, 42(1): 39-53.

[14] Jones, J. R., \& Harter, J. K. Race effects on the employee 84 engagement turnover intention relationship. Journal of Leadership \& Organizational Studies, 2005, 11(2): 78-82.

[15] Kahn, W. A. Psychological conditions of personal engagement and disengagement at work. Academy of Management Journal, 1990, 33(4): 692-724.

[16] Lawler, E. E., \& Hall, D. T. Relationship of job characteristics to job involvement, satisfaction, and intrinsic motivation. Journal of Applied Psychology, 1970, 54(4): 305-312.

[17] Lodahl, T. M., \& Kejnar, M. The definition and measurement of job involvement. Journal of Applied Psychology, 1965, 49(1): 24-33.

[18] Lucas, R. E., Diener, E., \& Larsen, R. J. Measuring positive emotions. In S. J, 2003.

[19] Morris, J. A. \& Feldman, D. C. The dimensions antecedents and consequences of emotional labor. Academy of Management Review, 1996, 21(4): 986-1010.

[20] Mowday, R. T., Porter, L. W., \& Steers, R. M. Employee-organization linkages: The psychology of commitment, absenteeism, and turnover. New York: Academic Press, 1982.

[21] Plutchik, R. Emotion. New York, NY: Harper \& Row, 1980.

[22] Putnam, L. L., \& Mumby, D. K. Organizations, emotion and the myth of rationality. In S. Fineman (Ed.), Emotion in organizations. London: Sage, 1993.

[23] Rafaeli, A., \& Sutton, R. I. Untangling the Relationship between Displayed Emotions and Organizational Sales: The Case of Convenience Stores. Academy of Management 
Journal, 1988, 31(3): 461-487.

[24] Rafaeli, A., \& Sutton, R. I. Expression of emotion as part of the work role. Academy of Management Review, 1987, 12: 23-37.

[25] Schaufeli, W. B., \& Salanova, M. Work engagement: An emerging psychological concept and its implications for organizations. In S. W. Gilliland, D. D. Steiner, \& D. P. Skarlicki (Eds.), Managing social and ethical issues in organizations (pp. 135-180). Charlotte, NC: Information Age Publishing, 2007.

[26] Schaufeli, W. B., Salanova, M., González-Romá, V., \& Bakker, A. B. (). The measurement of engagement and burnout: A two sample confirmatory factor analytic approach. Journal of Happiness Studies, 2002, 3: 71-92.

[27] Seeman, M. Alienation and engagement. In A. Campbell \& P. E. Converce (Eds.), The human meaning of social change. New York: Russell Sage Foundation, 1972.

[28] Shang-Ping, Lin. A study of the development of emotional labor loading scale. Sun Yat-Sen Management Review, 2000, 8(3): 427-447.

[29] Tsung-Yu Wu. Emotional Labor in the Interaction between Supervisors and Subordinates: Review, Clarification, and Prospect, Journal of human resources management, 2013, 13(3): 57-105

[30] Tsung-Yu Wu. Emotional labor at work: Development of concept, analysis of related variables, and exploration of psychological process issues. Taiwan University, 2003.

[31] VanMaanen, J., \& Kunda, G. Real feelings: Emotional expression and organizational culture. In L. L. Cummings \& B. M. Staw (Eds.), Research in organizational behavior, 1989, 11: 43-103. Greenwich, CT: JAI Press.

[32] Xiaojun Lu \& Mary E. Guy. How Emotional labor and Ethical Leadership Affect Job Engagement for Chiness Publish Servants, Public Personnel Management, 2014, 43(1), 3-24.

[33] Xiao-Ping Chen, Anne S. Tsui, Jiing-Lih Farh, Bor-Shiuan Cheng. Empirical methods for research in organization and management, Hwatai publishing, 2008. 